\title{
Handbook of Individual Differences, Learning, and Instruction
}

- Title: Handbook of Individual Differences, Learning, and Instruction. 1st ed.

- Author: David H. Jonassen, Baebara L. Grabowski

- Publisher: Routledge, 1993

교수-학습 장면에서 교수방법, 교수조건, 교수성과를 수업의 3대 변인이라 말한다. 교수방법은 교수자가 교육학의 여러 이 론이나 경험을 바탕으로 수업의 내용을 조직하고, 전달하고, 관리하는 방법을 의미하며, 교수조건은 교과의 내용, 목적, 제 약조건 및 학습자 특성을 말한다. 교수성과는 교수자의 교육활 동의 결과로 달성하게 될 수업의 효과를 의미한다. 최적의 교수 성과를 달성함에 있어, 지금까지 많은 주목을 받아온 변인인 교수방법은 교수자가 수업과정에서 다양한 방법을 선택적용할 것을 요구하여 왔다. 이와는 달리 3대 변인들 가운데 교수자가 숙명처럼 받아들이고 이해해야 하는 변인이 있는데, 이것이 바 로 교수조건이며, 이 가운데 특히 학습자특성이 그러하다. 교육 목표 자체가 학습자의 성향을 바꾸는데 있지 않다면 수업과정 에서 교수자가 교수방법을 다르게 선택할 수는 있어도 내성적 인 학습자를 외향적인 학습자로 바꾸어서 수업할 수 없기 때문 이다. 교육의 출발점은 학습자를 이해하는 데서 시작한다는 말 이 있다. 그렇다면 교수자는 나의 수업을 듣는 학생이 어떠한 특성을 가진 학습자인가를 잘 파악하는 일이 교수활동의 첫 걸음이 될 것이다.

이러한 관점에서 본다면 이 책은 가르치는 일을 맡고 있는 교수자에게 학습자를 이해할 수 있는 개괄적이면서도 소중한 정보를 제공하는 책이라고 할 수 있다. 이 책은 학습과 교수(수 업) 과정에서 교수성과에 영향을 줄 수 있는 개인차의 영역에 관하여 소개하고 있으며, 총 7부 33장으로 구성되어 있다. 특히, 개인차 영역을 크게 6 가지로 구분하여, 각 장마다 개인차 특성 을 한 가지씩 설명하고 있다. 도입부는 개인차, 학습, 수업과의 관계와 어떤 개인차가 학습과 수업에 어느 정도 영향을 주는가 에 대한 모형을 제시하고 있다. 2 부에서는 지능(intelligence) 을 구성하고 있는 요소에 대한 3가지 모형을 소개하고 있으며, 3 부와 4부에서는 인지제어(cognitive control)와 인지양식 (cognitive style)에 대한 다양한 유형을 소개하는데, 유기체가 환경과 상호작용하면서 정보를 인지하고, 조직하고, 처리하는

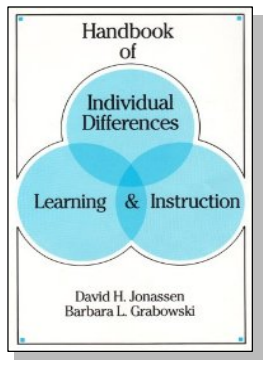

방식에 대하여 기술하고 있다. 5 부에 서는 학습자가 선호하는 학습방식을 검사할 수 있는 세 가지 종류의 학습 양식(learning style)을 소개하고, 6 부에서는 성격(personality)을 다루 는데, 학습자가 가질 수 있는 다양한 정서적 특성과 동기를 소개하고 있 다. 마지막 7부에서는 학습자가 가진 선행지식(prior knowledge)의 종류 와 수업에 미치는 영향을 소개하고 있다. 각 장에서는 그 장에서 다루고 있는 개인차 특성에 따라 상이한 수업방법을 처치한 연구논문들의 결과를 소개하고 있어 참고할 만하다.

1990년대 이후 우리나라 의과대학에서는 대대적인 교육과정 개편이 있었다. 그 교육과정 개편의 특성에 포함된 철학을 살펴 보면, 학습자 중심의 교육과정이 중요하게 자리 잡고 있음을 알 수 있다. 이 책은 학습자 중심 교육과정의 이론적 전제가 될 수 있는 학습자 특성의 다양성과 학습에서 개인 차이가 발생 하는 이유를 이해하는 데 도움이 될 수 있으며, 무엇보다도 학습 자의 특성을 고려하여 수업방법을 다르게 처방하고자 할 때 가이드 역할을 할 수 있기 때문에 두고두고 곁에 두면서 참고할 만한 서적이라 여겨진다.

여상희, 경북대학교 의학전문대학원 의학교육학교실 Sang Hee Yeo, Department of Medical Education, Kyungpook National University School of Medicine, Daegu, Korea

\footnotetext{
Korean J Med Educ 2010 Jun; 22(2): 151. doi: 10.3946/kjme.2010.22.2.151.

pISSN: 2005-727X elSSN: 2005-7288

(C) The Korean Society of Medical Education. All rights reserved.
} 